Roso, A.; Strey, M.N.; Guareschi, P.; e Bueno, S.M.N.

"Cultura e ideologia: a mídia revelando estereótipos raciais de gênero"

\title{
CULTURA E IDEOLOGIA: A MÍDIA REVELANDO ESTEREÓTIPOS RACIAIS DE GÊNERO
}

\author{
Adriane Roso \\ Marlene Neves Strey \\ Pedrinho Guareschi \\ Sandra M. Nora Bueno \\ Pontifícia Universidade Católica de Porto Alegre
}

RESUMO: Nesse artigo, analisamos duas formas simbólicas brasileiras (comerciais de televisão) tendo como enquadre teórico uma metodologia crítica baseada em alguns elementos teóricos dos Estudos Culturais. O ponto de partida é o conceito de minoria e maioria, e seu caráter nômico e anômico. Assumimos que as formas simbólicas podem ser entendidas como portadoras de ideologia, e para entender a ideologia subjacente a elas nós temos que desconstruir a unidade da mensagem e expor sua "naturalidade". Nesse processo, aspectos relacionados às relações de dominação de gênero e raça foram desveladas, indicando que a discriminação em direção às minorias ainda é parte da nossa realidade mediada.

PALAVRAS-CHAVE: Psicologia social; Estudos Culturais; mídia brasileira; relações de gênero e raça

\section{CULTURE AND IDEOLOGY: THE MEDIA REVELING RACIAL AND GENDER STEREOTYPES}

ABSTRACT: In this article we analyze two Brazilian symbolic forms (television commercials) having as theoretical framework a critical methodology based on some theoretical elements of Cultural Studies. The starting point is the concept of minority versus majority, and its nomic and anomic character. We assume that symbolic forms can be understood as carriers of ideology, and in order to understand its underpinned ideology we have to deconstruct the messages unity and expose its "naturality". In this process issues regarding gender and racial relations of domination were unveiled, indicating that discrimination towards minorities still takes part of our mediated reality. 
KEY-WORDS: Social Psychology; Cultural Studies; Brazilian media; gender and racial relations.

\section{CULTURA E IDEOLOGIA: A MÍDIA REVELANDO ESTEREÓTIPOS RACIAIS E DE GÊNERO}

Todos os dias quando ligamos a televisão, nosso espaço privado é invadido por uma série de programas de auditório, noticiários, novelas e filmes. No geral, escolhemos o programa que queremos ver. Se um filme não agrada, por exemplo, pressionamos o botão do controle remoto e transformamos as imagens que não nos agradam, ou não nos interessam, em algo, no mínimo, aceitável. Mas será que o mesmo ocorre com as propagandas que intercalam o programa escolhido por nós? Na maioria das vezes, provavelmente não. Afinal, as propagandas duram 30 segundos cada. Suas imagens passam quase que desapercebidas pela nossa consciência, ou seja, as pessoas não costumam parar para prestar atenção ao seu conteúdo da mesma forma que prestam atenção a algo específico de seu interesse (como uma novela, ou um noticiário). Elas podem servir como um "descanso" para nossa mente e, ao voltarmos a assistir o programa "escolhido" por nós, temos a atenção revigorada. Mais do que isso, como lembra Barthes (1989), as imagens intencionais transmitidas pelos meios de comunicação são consumidas inocentemente ${ }^{1}$ pelo público, que não as vê como sistemas de valores, mas como fatos dados, um processo natural.

Consciência é um termo importante para a Psicologia Social Crítica pois está relacionado à questão da dicotomia teoria-prática, entre o falar e o fazer. Busca-se, através desse paradigma, romper com a alienação que cria e fortalece as injustiças sociais. A consciência é entendida aqui como aquilo que recebo de resposta à pergunta "Por que sou o que sou?, Por que aquilo que me rodeia é assim?". O aumento da consciência leva à maior liberdade. Quanto mais respostas consigo dar a essa pergunta, maior minha consciência. A consciência crítica leva a uma consciência ética, a uma responsabilidade; uma responsabilidade que vem de dentro e não de fora, imposta. Então, quando assistimos a uma propaganda sem nos questionarmos sobre ela, podemos estar correndo o risco de sermos aprisionados, manipulados, e a Psicologia Social Crítica alerta justamente para essa manipulação da consciência.

Precisamos ficar atentos/as às práticas veiculadas nos meios de comunicação de massa, já que é dentro de um processo quase mágico, veloz 
Roso, A.; Strey, M.N.; Guareschi, P.; e Bueno, S.M.N.

"Cultura e ideologia: a mídia revelando estereótipos raciais de gênero"

e sutil que mensagens - formas simbólicas -, dos tipos mais diversos, passam a interagir com as diversas culturas, criando representações e transformando relações. Interagir é um termo essencial aqui, visto entendermos que a cultura se relaciona diretamente com a produção e a troca de significados entre os membros de uma sociedade ou de um grupo.

$\mathrm{Na}$ interação cultural, as formas simbólicas, segundo Thompson (1995) implicam cinco características básicas. A primeira, é que elas são sempre intencionais, querendo dizer que são sempre a expressão de um sujeito para outro. A segunda, é que elas são convencionais, ou seja, a produção, a construção ou o uso delas, bem como a interpretação das mesmas, são processos que envolvem regras, códigos ou convenções. A terceira característica é que elas são estruturais, isto é exibem uma estrutura articulada e, ao fazermos a análise da estrutura, devemos investigar não somente seus elementos específicos, mas também suas inter-relações. A quarta característica é seu aspecto referencial, já que as construções representam algo, referem-se a algo, dizem algo sobre alguma coisa. A quinta e última característica é o seu aspecto contextual, pois as formas simbólicas são sempre inseridas em processos e contextos sócio-históricos específicos dentro dos quais e por meio dos quais elas são produzidas, transmitidas e recebidas.

Um sério problema surge quando as formas simbólicas de determinada propaganda são criadas, ou contribuem, para reforçar e estabelecer relações de dominação ou de exclusão, as quais ocorrem quando uma pessoa, ou grupo de pessoas, possui poder de uma maneira permanente, e em grau significativo, permanecendo inacessível a outra(s) pessoa(s), independente da base sobre a qual tal exclusão é levada a efeito.

É nesse momento que as formas simbólicas, na dimensão cultural, passam a carregar consigo relações ideológicas, conforme definidas por Thompson (1995). Um dos passos para romper com esta ideologia é analisá-la, ou seja, estudar as maneiras como as formas simbólicas se entrecruzam com as relações de poder. Em outras palavras, como o sentido pode servir para estabelecer, sustentar e reforçar relações de dominação.

\section{RELAÇÕES DE DOMINAÇÃO: MAIORIA VERSUS MINORIA}

Uma relação de dominação pode ser estabelecida de diversos modos. Podemos falar de relações de dominação de gênero, relações de dominação de classe, de raça, etc. Elas também podem ser o somatório de todos esses tipos de relações de dominação. Um tipo não é mais grave do 
Psicologia \& Sociedade; 14 (2): 74-94; jul./dez.2002

que o outro, pois, no fim das contas, o resultado de qualquer um é o agravamento do processo de exclusão, ou seja, são extraídas das pessoas seus direitos à cidadania simplesmente por pertencerem a determinada classe social, por serem de determinada raça, ou representarem um gênero específico.

O processo de exclusão abarca a pessoa que exclui e a que é excluída, ou a pessoa que discrimina e aquela que é discriminada. No campo da pesquisa social americana e européia, o binômio maioria-minoria tem sido amplamente empregado para o entendimento desse processo. Nos países em desenvolvimento e "subdesenvolvimento", parece que essa expressão ainda não ganhou a importância devida. No Brasil, falamos dos/as negros/ as, das mulheres, dos/as índios/as, mas poucos são os estudos que adotam o binômio "maioria/minoria" para o entendimento e análise dos fenômenos culturais, e consideramos importante incluir estas terminologias no campo da pesquisa social.

Como podemos definir os termos "maiorias" e "minorias"? Moscovici (2000) salienta que a maioria é definida em termos de minorias e minorias em termos de maioria; eles são termos mutuamente interdependentes. Aqui, definiremos esses termos não em termos numéricos, mas em termos de relações de poder. Utilizaremos o termo maioria para nos referirmos a qualquer grupo de pessoas que controle a maior parte de recursos econômicos, de status e de poder, estabelecendo, assim, relações injustas com as minorias sociais.

Já minorias podem ser definidas como segmentos das sociedades que possuem traços culturais ou físicos específicos que são desvalorizados e não inseridos na cultura da maioria, gerando um processo de exclusão e discriminação. Minoria (assim como maioria) não tem a ver, pelo menos para nosso estudo, com questões numéricas. Por exemplo, nosso país é constituído por um número expressivo de mulatos/as e negros/as, mas eles/as são minorias, pois são constantemente discriminados, depreciados e excluídos.

A construção das representações sociais sobre as minorias e o estabelecimento das relações sociais e culturais entre minorias e maiorias não são conseqüência natural destes traços culturais ou físicos, mas, sim, uma construção social que é circunscrita por forças de relações políticoeconômicas. O significado do termo minoria varia de acordo com a cultura e o momento histórico.

Basicamente, as minorias são consideradas como existindo na fronteira social, ou mesmo fora dela. A situação de uma minoria, é a situ- 
Roso, A.; Strey, M.N.; Guareschi, P.; e Bueno, S.M.N.

"Cultura e ideologia: a mídia revelando estereótipos raciais de gênero"

ação de um grupo ao qual foi negada autonomia e responsabilidade, que não tem a confiança, nem é reconhecido por outros grupos. Tal grupo não se reconhece nos sistemas existentes de poder e crença e ele não representa tal sistema para ninguém (Moscovici, 2000). Desse modo, quando um grupo minoritário deseja introduzir um elemento novo, perturbador, em um grupo, ele carece de poder e, às vezes, da competência necessária para impor seu ponto de vista a uma população de maior importância. Quando tentam, são depreciados, postos ao ridículo (Doms e Moscovici, 1991). A luta dos homossexuais pelo direito ao casamento civil pode servir como exemplo de um grupo minoritário tentando introduzir elementos inovadores na sociedade. Diversos segmentos da sociedade são contrários a essa inovação como, por exemplo, a Igreja Católica Romana e os Mórmons, que mostraram sua oposição à homossexualidade em geral e à união civil dos homossexuais em particular (veja Johnson, 2000 e Morello, 1999).

Isto pode gerar uma relação de opressão onde, a partir do olhar da maioria, o "outro" (minoria) se apresenta com uma conotação negativa, e a "maioria", uma positiva. As pessoas não podem ser como querem; têm que ser como a maioria (e.g., casar com uma pessoa do sexo oposto; não abusar de drogas ilícitas), ou serão consideradas desviantes, inadaptadas ou marginais. Nessa relação de opressão, os estereótipos surgem e se cristalizam.

Como discute Hall (1997), estereotipar faz parte da manutenção da ordem social e simbólica, estabelecendo uma fronteira entre o "normal" e o "desviante", o "normal" e o "patológico", o "aceitável" e o "inaceitável", o que "pertence" e o que "não pertence", o "nós" e o "eles". Estereotipar reduz, essencializa, naturaliza e conserta as 'diferenças', excluindo ou expelindo tudo aquilo que não se enquadra, tudo aquilo que é diferente.

No momento em que se atribuem estereótipos às pessoas, duas alternativas possíveis, que interagem, apresentam-se: conformar-se ou não se conformar à maioria.

Uma definição simples de conformidade é dada por Levine e Pavelchak (1991, p.43): "existe conformidade quando um indivíduo modifica seu comportamento ou atitude a fim de harmonizá-los com o comportamento ou atitude de um grupo". Todavia, esse não é um processo linear, estanque ou imutável, até porque um grupo minoritário pode conformar-se por não estar consciente da existência de uma relação de dominação e conformar-se porque não encontra meios de rebelar-se. Quer dizer, ora o indivíduo se conforma, ora não. Às vezes, tem consciência desta relação de dominação, mas as pessoas não conquistaram o poder de 
Psicologia \& Sociedade; 14 (2): 74-94; jul./dez.2002

reivindicar seus direitos para transformar tal situação.

Para explicarmos o não se conformar precisamos recorrer aos conceitos usados por Moscovici: caráter nômico (ativo) ou anômico (passi$v o$ ). A presença ou ausência de uma posição definida, de um ponto de vista coerente, de uma norma própria, é que converte uma minoria em uma pessoa ativa ou passiva em suas relações sociais. Assim, "o primeiro sinal distintivo de uma minoria, autora de um processo de inovação, está relacionado com sua oposição consciente à norma da maioria e com sua adesão firme, com sua defesa de uma contra--norma que fazem dela um sócio ativo potencial nas relações sociais" (Moscovici, 1991, p.79).

Uma minoria que quer inovar está indo contra uma ordem estabelecida pela maioria. Para manter a ordem da dualidade excluídos/asexclusores/as, discriminados/as-discriminadores/as, recursos ou meios são utilizados (consciente ou inconscientemente) pela maioria, tal como os meios de comunicação de massa através das propagandas. Este processo de exclusão é criado e se desenvolve dentro de contextos culturais historicamente construídos, mas é através da midiação que estes meios conseguem estabelecer - e que hoje se tornam centrais à compreensão de nossa cultura - que o processo de exclusão amplie seu espaço e alimente sua força. A midiação da cultura moderna, para Thompson (1995), é o processo geral através do qual a transmissão das formas simbólicas se torna sempre mais mediada pelos aparatos técnicos e institucionais das indústrias da mídia: "Vivemos, hoje, em sociedades onde a produção e a recepção das formas simbólicas é sempre mais mediada por uma rede complexa, transnacional [grifo nosso], de interesses institucionais"(p.12).

A exclusão se processa não somente em termos do real, do concreto, mas do virtual, extrapolando o tempo e o espaço, aumentando o espectro em que a exclusão pode ser criada e reforçada. O movimento pode ser sutil, mas muito produtivo: o sistema, através da mídia e de outros recursos, procura transformar "o diferente" (minoria) em "o igual" (maioria). Quanto mais pessoas agirem de forma massificada, mais se pode vender em uma sociedade de consumo.

O império da moda e da tecnologia tem se apropriado muito bem dessa idéia, pois quanto maiores os desejos padronizados em relação a determinado estilo de vestimenta/tecnologia, maior será a venda. Em uma sociedade modernizada, é muito mais fácil produzir em grande escala peças para uma maioria, como jeans, acessórios, computadores, telefones, etc. Assim, tentar transformar os desejos das minorias nos mesmos desejos da maioria, torna-se imprescindível em uma sociedade capitalista. 
Roso, A.; Strey, M.N.; Guareschi, P.; e Bueno, S.M.N.

"Cultura e ideologia: a mídia revelando estereótipos raciais de gênero"

O paradoxo disto é que se procura, dentro deste "modelo padronizado", criar a ilusão de seres diferenciados, únicos. Não com o intuito de reforçar um senso de comunidade, mas para acentuar características de uma sociedade cada vez mais individualista, onde o comportamento de consumo é um dos mais incentivados.

\section{OPERACIONALIZANDO UMA LEITURA IDEOLÓGICA}

Assumindo que as formas simbólicas podem ser entendidas como portadoras de ideologia, isto é, como criadoras e mantenedoras de relações de dominação, podemos agora passar a assistir às propagandas não mais com olhos de telespectadores/as, mas como pesquisadores/as críticos/as, prestando atenção em quem expressa o que e como isto é representado, ficando atentos/as às regras, códigos ou convenções utilizados, à estrutura específica e às inter-relações que perpassam a propaganda. Devemos buscar entender o que elas representam, a que elas se referem e o que está sendo dito, sem esquecer que a propaganda é produzida e recebida a partir de um determinado contexto sócio-histórico.

Palavras, imagens, mensagens, ou qualquer outra forma simbólica seriam inofensivas se não carregassem ideologia consigo, se não estivessem promovendo interesses de grupos de pessoas que, consciente ou inconscientemente, discriminam aqueles/as que são minorias. De fato, como argumenta Verón (citado em Heck, 1996), “a ‘ideologia' não é um tipo especial de mensagem, ou uma classe social de discursos, mas é um dos muitos níveis de organização das mensagens, do ponto de vista de suas propriedades semânticas. Ideologia é, conseqüentemente, um nível de significação, o qual pode estar presente em qualquer tipo de mensagem, mesmo no discurso científico. Qualquer material de comunicação social é suscetível de uma leitura ideológica" (pp.123-124).

Nesta perspectiva, podemos entender ideologia também como "um sistema de regras semânticas que expressam certo nível de organização das mensagens. Seria somente através do desembaraçamento dessas regras semânticas que nós chegaremos ao núcleo de uma mensagem. Entretanto, na análise de significados ideológicos, o 'núcleo' não se refere somente ao conteúdo da mensagem ou sua 'organização não-manifesta'. Quando uma mensagem é emitida, não somente o que é dito que tem um significado, mas também o modo como é dito, e o que é não dito, mas poderia ser dito. As significações em uma mensagem são estabelecidas pelos significados de um código e é esse código que permite que a mensagem seja organizada 
(...)" (Heck, 1996, p.124).

O código regula propensões, identidades e práticas. Regula o "que" e o "como" dos significados. O código pode ser encarado como um esforço para escrever gramáticas pedagógicas de habitus (gramática cultural especializada de acordo com a posição de classe e com os campos de prática) especializados e formas de transmissão que buscam regular sua aquisição. No processo de aquisição de códigos específicos, adquirem-se princípios de ordem, mas também, ao mesmo tempo, princípios tácitos de desordenamento dessa ordem (Berstein, 1996).

Esses códigos, de acordo com Berger (1991), são padrões altamente complexos de associações que aprendemos em uma determinada sociedade e cultura. São "estruturas secretas" na nossa mente que afetam o modo de interpretarmos os signos.

Esta acepção de ideologia não contradiz a acepção de Thompson (1995), para quem o conceito de ideologia pode ser usado para se referir às maneiras como o sentido serve para estabelecer e sustentar relações de poder que são sistematicamente assimétricas, ou seja, ideologia é sentido a serviço do poder.

Como podemos fazer essa leitura ideológica e desvelar essas "estruturas secretas", tornar visível, explícito aquilo que, muitas vezes, não vemos? Escolhemos duas propagandas para ilustrar um modo de analisar formas simbólicas, com o intuito de demonstrar alguns pontos básicos de uma metodologia crítica e levantar algumas questões sobre as relações de dominação de gênero e raça imbricadas nas propagandas Blue Steel e da Embratel 21, que foram veiculadas nos anos 1999-2000, nos canais convencionais da televisão brasileira (ver descrição das propagandas em Anexo).

\section{ANÁLISE DAS PROPAGANDAS}

Para desconstruir a unidade de uma mensagem e expor sua "naturalidade" como uma construção altamente ideológica, Fiske (1990) sugere que investiguemos três níveis que se entrecruzam, onde os códigos televisivos entram em cena: realidade, por exemplo, aparência, vestimenta, comportamento, discurso, etc.; representação, como o uso da câmera , luz, música, narrativa, ação, conflito, etc.; e ideologia, relações assimétricas já sedimentadas ou não, como patriarcado, diferenças de raça, classe e gênero.

Ao nível da realidade, encontramos nas propagandas inúmeros 
Roso, A.; Strey, M.N.; Guareschi, P.; e Bueno, S.M.N.

"Cultura e ideologia: a mídia revelando estereótipos raciais de gênero"

códigos que já fazem parte do cotidiano das pessoas. Como lembra Fiske (1990), a aparência na vida real já é codificada; quando nós fazemos sentido das pessoas pela sua aparência, nós fazemos isso de acordo com os códigos convencionais de nossa cultura. A realidade já é codificada, ou melhor, o único modo através do qual nós podemos perceber e dar sentido à realidade é através dos nossos códigos culturais. O que passa por realidade em qualquer cultura é o produto desses códigos culturais. Desse modo, a realidade está sempre codificada, ela nunca é matéria bruta.

A partir da vestimenta utilizada na propaganda Blue Steel, podemos dividir os personagens em dois grupos distintos: de um lado, um casal composto por um homem branco, cabelos castanhos e curtos, olhos verdes, vestindo calça jeans, camisa jeans clara aberta e por fora das calças, carregando uma mochila nas costas; e uma mulher branca, cabelos loiros e longos, olhos verdes, vestindo calça marrom e camiseta bege, e à tira-colo, uma bolsa tipo "estudante".

Por outro lado, temos quatro jovens. Dois deles são negros, usam cabelos totalmente raspados. Um dos rapazes negros usa brinco de argola na orelha esquerda, pulseira no braço direito e anel no dedo direito; veste calça e colete de vinil preto, que está aberto e sem nada por baixo. Há uma corrente que está presa ao cinto e a outra ponta está no bolso. Possui tatuagens grandes em ambos os braços. O outro está vestindo calça militar e colete preto, fechado. $\mathrm{O}$ terceiro rapaz aparenta ser latino e usa um lenço, tipo "pirata", cobrindo os cabelos. Está de óculos escuros e veste um bermudão de cor clara e camiseta boxer preta. Está usando uma gargantilha preta. O quarto rapaz é branco, tem cabelos loiro--escuros, curtos e ondulados. Na testa, está amarrado um lenço, tipo "ninja". Veste uma camiseta boxer branca e usa colar no pescoço.

Pela descrição podemos ver que existe um estilo "clean", típico da classe social média ou média alta, representado pelo jovem casal, que pretende ser imitado pelo grupo de rapazes. A mensagem que se tenta passar é: "Se conseguir aquele jeans vou ficar tão maneiro quanto aquele rapaz". Este é o nível da realidade, onde o abarrotamento das lojas de departamento é a prova da existência desse desejo imperativo.

Na propaganda da Embratel, podemos observar a mesma divisão, que é representativa da realidade em que vivemos. De um lado, temos a protagonista que anuncia o serviço. É uma mulher branca, jovem, cabelos castanhos e longos, olhos verdes, vestindo uma roupa branca onde somente aparece a gola. Há também um casal branco. Ele, um português aparentando aproximadamente 60 anos, obeso, usando uma calça escura e um 
Psicologia \& Sociedade; 14 (2): 74-94; jul./dez.2002

jaleco branco. Ela, também portuguesa, com aproximadamente 50 anos, branca, cabelos pretos curtos e obesa. Está vestindo um vestido estampado, com um pano no ombro direito e um rolo de massa na mão esquerda.

Do outro lado, temos uma jovem negra, com cabelos pretos e com uma tiara de renda, vestindo um uniforme de empregada doméstica, bem curto e justo, marcando a roupa íntima.

Uma jovem negra vestindo um uniforme sexy de empregada doméstica, ou um jovem negro tatuado com os cabelos raspados, vestindo roupa de vinil preto, por exemplo, já estão codificados mesmo antes de serem filmados e transformados em propaganda. Inferimos a classe social dos personagens da propaganda simplesmente pelo modo como se vestem e agem. O modo de vestir-se, ou de agir, é representante daquilo que a pessoa é, daquilo que ela faz ou deixa de fazer. É o retrato da realidade social em que se estamos inseridos.

Ao nível da representação, precisamos entender a relação entre significante, significado e signo. A semiótica (especialmente no que se refere às obras de Saussure e Barthes) nos apresenta conceitos e princípios importantes que ajudam na compreensão de formas simbólicas como os de significante, significado e signo. Simplificando o que já tem sido bastante estudado, podemos dizer que o significante é som-imagem, é a forma de alguma coisa; e o significado é o sentido que é gerado a partir do significante. O signo é uma combinação de um significado com o som-imagem. Ele designa o todo (mensagem); é a combinação do significado com o significante. No caso da propaganda Blue Steel temos o jeans (significante), que produz um significado (moderno, status, felicidade, versátil, universal). A combinação destes dois produz o signo, ou seja a mensagem: para ser igual à maioria, basta vestir o jeans Blue Steel.

Deste modo, ao comprar uma calça jeans, não estou simplesmente comprando uma roupa. Estou comprando algo que me faz estar na moda, faz com que eu não mais me sinta diferente da maioria e, não sendo diferente, não serei excluído/a, discriminado/a. Vestir um jeans passa a ser o passaporte que vai me transportar do mundo da minoria para o mundo da maioria (ou assim se espera).

O jeans limpo e claro vestido pela maioria (bela, ativa, estudiosa) e um grupo minoritário (rebeldes, tatuados, ociosos) desejando ser como aquela maioria, forma o cenário perfeito para a venda de um produto que tem estado relativamente fora de moda entre os grupos minoritários, que têm adotado estilos diferentes como o grunge, o dark ou afro-brasileiro. Adaptar, moldar, transformar o anti-estético para a maioria para que as 
Roso, A.; Strey, M.N.; Guareschi, P.; e Bueno, S.M.N.

"Cultura e ideologia: a mídia revelando estereótipos raciais de gênero"

diferenças sejam amalgamadas, amenizadas e, portanto, não discutidas. Como diz Berger (1991), quando temos o apropriado significante "capturamos" o apropriado significado. Assim é que as propagandas funcionam. As pessoas compram os produtos "certos" esperando que esses produtos signifiquem certo status social, estilo de vida, etc.

Na propaganda da Embratel 21, temos o serviço da Embratel (significante), que produz um significado: atenuante da saudade, aproximação das pessoas, mudança nas relações. A combinação dos dois produz a mensagem (signo): ao utilizar o 21 quebram-se as barreiras espaciais e temporais entre as pessoas.

Ao escolher o serviço da Embratel, ou escolher o jeans Blue Steel, estou acreditando na possibilidade de me aproximar das pessoas, daqueles que estão longe de mim, rompendo qualquer barreira, sejam elas espaciais, temporais, raciais ou de gênero. Pouco importa se estou em Nova Iorque ou no Brasil, em Salvador ou no Sul. Cria-se a ilusão de um mundo onde todos são iguais, ou que pelo menos precisam ser iguais. Entretanto, parecer igual ou estar "ligado" a todo mundo fica somente no imaginário, porque uma mudança nas relações sociais estabelecidas exigiria a substituição da supervalorização dos aspectos formais (aparentes) pela valorização da ética.

A relação entre o significante e o significado é arbitrária; quer dizer que os significados precisam ser aprendidos. De alguma forma, o que está implícito é que existem certas associações estruturadas, ou códigos, que nos ajudam a interpretar os signos (Berger, 1991). Tomemos o caso das tatuagens. Alguns dos personagens do grupo minoritário que aparecem na propaganda do jeans são tatuados. O que significa uma tatuagem? Quais os códigos - ou as estruturas secretas - envolvidos nesse caso? Uma tatuagem representa o quê na sociedade? Maior dificuldade de conseguir bons empregos? Não poder doar sangue? Pertencer à classe economicamente desfavorecida? Ser marginal?

Tomemos como ilustração o caso de John Baldetta, um auxiliar de enfermagem nos Estados Unidos, que foi demitido quando se recusou a cobrir sua tatuagem que dizia "HIV POSITIVO” (Modern Healthcare, 1993). Claramente, tatuagem aqui representa discriminação, já que implicou a demissão do auxiliar. Outro exemplo: Congressista americano recentemente garantiu recursos financeiros federais no valor de US\$50,000 para remoção de tatuagem na cidade de Santa Barbara, CA (The Weekly Standard; 2002). Por que se faz necessário garantir essa quantia de dinheiro para remoção de tatuagens? Não seria isso um indicador de que, devido à discriminação aos tatuados, é preciso criar fundos especiais 
$=$ Psicologia \& Sociedade; 14 (2): 74-94; jul./dez.2002

a esse fim?

Os achados do estudo intitulado "Tatuagem e piercing oferecem pistas psicopatológicas" (Journal of Psychosocial Nursing \& Mental Health Services, 1998), também podem nos ajudar a refletir sobre a possibilidade de discriminação aos tatuados. Os autores afirmam que pacientes psiquiátricos com tatuagem e piercing são mais ansiosos do que pacientes sem esses adornos, apresentam um índice maior nas escalas de auto-mutilação e de comportamento anti-social e tendem a apresentar mais comportamentos de risco.

É nossa opinião que parece existir uma representação negativa da pessoa tatuada na nossa sociedade. Assim, pessoas bem posicionadas na sociedade, pessoas "de bem" não se comportam mal, não colocam marcas no corpo para serem diferentes. A maioria precisa preservar seu corpo, sua imagem, e os estigmas ficam como emblemas das minorias.

Ainda no plano representacional, podemos observar que o grupo de rapazes minoritários da propaganda Blue Steel parece estar bem confortável, reunido em frente a um prédio que aparenta ser de famílias de baixo poder aquisitivo, característico de cidades como Nova Iorque. O casal de brancos anda em um território que parece não ser o seu. $\mathrm{O}$ grupo minoritário enfrenta e afronta o casal, mas mesmo assim o casal é "valente", demonstra não temer o ataque. Dá-se as mãos e pisa firme, continuando sua caminhada. A música atinge tons mais fortes, criando um clima de tensão. Isso nos faz lembrar as reações tão comuns em assaltos: os bandidos (minorias) atacam e as vítimas (maiorias) reagem. A culpa nunca é da vítima que reagiu, mas do bandido que atacou.

A fala final (e única) unidirecional, parte do rapaz negro. É uma fala impositiva, autoritária, afrontadora. $\mathrm{O}$ rapaz olha para o rapaz branco de cima para baixo. O movimento de pan down ${ }^{2}$ da câmera (significante), de acordo com Berger (1991), gera um significado de poder, autoridade. Este é o momento em que a minoria tem poder de reivindicar seu desejo, mas essa reivindicação sustenta-se sobre o desejo da maioria. É uma tentativa de extrair o que a maioria tem - no caso o jeans. Nos assaltos não é diferente, pois o bandido quer extrair tênis, roupas, dinheiro, carro, etc. A diferença entre a situação da propaganda e de um assalto real é que o rapaz negro não rouba; ele simplesmente quer saber onde o rapaz branco comprou o jeans. Mas será que ele terá dinheiro para comprar em uma loja de classe média? São as contradições da nossa sociedade consumista, pois ao mesmo tempo em que se quer que todos tenham acesso aos produtos, não se dá condições para que a minoria adquira o que é veiculado. A propaganda suscita 
Roso, A.; Strey, M.N.; Guareschi, P.; e Bueno, S.M.N.

"Cultura e ideologia: a mídia revelando estereótipos raciais de gênero"

um desejo na minoria que, muitas vezes, é impossível de ser alcançado. Há uma produção capitalista de desejos; produção maquiavélica e sórdida.

O mesmo vale para a propaganda da Embratel. Quem tem o telefone? O casal português. A moça negra tem que pedir um favor - usando dos artifícios da sedução - para poder fazer o 21 . O uso da imagem de mulher negra, sensual, sedutora, tem sido uma estratégia amplamente utilizada na mídia, reforçando um estereótipo de gênero.

É comum ouvirmos comentários, ou piadas, insinuando que quando se vê um negro bem vestido com roupas de marca ou com um carro bom ou do ano, só pode ser jogador, motorista ou ladrão, como se este negro não pudesse ter os mesmos bens que a maioria possui. São, outra vez, as contradições, da nossa sociedade, em que ao mesmo tempo em que força todo mundo a adquirir, quando a minoria chega a possuir, questiona-se como ela o conseguiu.

Interessante ainda pontuar que no início da propaganda Blue Steel quem está em movimento é o casal de brancos, caminhando pela calçada, com mochila e bolsa de estudante. Já o grupo de rapazes está parado, sem fazer nada, causando a impressão de "vadiagem". Somente quando o ataque dos rapazes vai acontecer, que eles se movimentam rapidamente, como um felino que vai dar um bote na presa, como vagabundos ou como assaltantes bem experientes.

Igualmente a moça que vai fazer um telefonema, na propaganda da Embratel, passa a mesma mensagem. O que estaria ela fazendo de uniforme em um botequim, enquanto a maioria (Seu Joaquim e sua esposa) está trabalhando? Por que a moça negra está com um uniforme tão curto, como se ela precisasse seduzir seu Joaquim?

Outro aspecto a salientar é quanto à quantidade de tomadas closeup do casal branco em relação ao grupo minoritário. Há bem mais closeups do casal e essa é uma das maneiras de produzir significados. Closeups, conforme Berger (1991) geralmente significam intimidade, simpatia. É preciso que sintamos simpatia pelo casal que usa o jeans e repulsa ou medo dos outros que estão vestidos fora da "normalidade" e do bom senso.

Os close-ups da propaganda Embratel são, em sua maioria, dedicados à moça negra, especialmente focalizando suas pernas ou nádegas, de modo a objetificar aquela pessoa, o que é mais uma forma de discriminação de gênero. Já os close-ups da esposa de Joaquim, acentuam sua brabeza: focam a boca aberta, gritando e, principalmente, o rolo de massa. Salienta-se a rivalidade entre as duas mulheres. Enquanto uma mulher é sedutora do marido, a outra é a esposa ciumenta. Caricaturar de forma 
Psicologia \& Sociedade; 14 (2): 74-94; jul./dez.2002

desarmoniosa as relações entre mulheres pode contribuir para que elas não se unam e percebam a si mesmas como pessoas discriminadas. $\mathrm{O}$ seu Joaquim é apenas um bom português que está ajudando a pobre menina a matar saudades.

Compreendendo o nível da realidade e o da representação, podemos aprofundar o mais difícil de ser desvelado: o nível da ideologia, que se mescla com os anteriores.

A escolha dos nomes dos produtos pode indicar a ideologia subjacente. O nome do jeans Blue Steel, por exemplo, significa "Aço Azul", remete a algo nobre e raro, como quando dizemos ter "sangue azul". Vestir um Blue Steel é vestir a possibilidade de ser nobre, de ser maioria. Além disso, vestir "aço" é como estar dentro de um escafandro ou armadura. Ele proporciona a força, a segurança de cruzar e enfrentar o perigo (minoria). Se a minoria usa o mesmo que maioria também pode passar a se sentir protegida e corajosa, tal como o casal branco da propaganda fez.

Mas o que o nome Blue Steel tem a ver com a realidade brasileira, ou com a realidade cultural gaúcha? Há muito sabemos que marcas estrangeiras vendem. O idioma inglês escolhido empresta também um caráter sofisticado à propaganda. Hoje em dia, falar inglês é um código representativo de que tenho educação e tenho dinheiro para investir em cursos de idioma e em viagens internacionais.

A escolha do nome "21" também foi inteligente e interesseira. Vinte e um é o novo século que está começando. Usar o " 21 " sugere transpor inúmeras barreiras, como a tecnológica, por exemplo. Há ainda muito por vir, por acontecer e, como em todo o início de um novo século, as esperanças se renovam. Quem sabe neste século não seremos todos iguais? Ou quem sabe no decorrer do século 21 os bens de consumo, no momento ainda privilégio da maioria, poderão ser acessíveis também às minorias?

O cenário escolhido para a propaganda do jeans é um indicador significativo de comunicação intercultural, já que as casas assemelham-se às construções novaiorquinas. Comunicação intercultural é definida por Richard Porter e Larry Samovar (citado em Mulvaney, 1994) como aquela que ocorre quando um produtor de mensagem é membro de uma cultura e o receptor/a é membro de outra. O uso de espaços ajuda a definir as relações sociais e as hierarquias.

Nova Iorque tem status, Nova Iorque é um centro de compra de roupas, Nova Iorque tem o sabor da mistura étnica, racial e de tudo o mais ${ }^{3}$. Se há discriminação racial, a propaganda não mostra claramente. Ao contrário, negros, brancos e latinos vivem em grupo, como se a rivalidade, que 
Roso, A.; Strey, M.N.; Guareschi, P.; e Bueno, S.M.N.

"Cultura e ideologia: a mídia revelando estereótipos raciais de gênero"

sabemos existir entre eles, formando até gangues, fosse irreal. Para nós brasileiros/as talvez isso seja difícil de perceber, pois não nos sentimos latinos do mesmo modo que um latino que mora nos EUA se sente. As formas simbólicas viajam no espaço e no tempo, redobrando sua força e ganhando um caráter universal e globalmente aceito. As propagandas conseguem capturar e juntar minorias diversas, ganhando força na sua intenção de massificar, de transformar o modo peculiar das minorias no jeito igual ao das maiorias.

No caso da propaganda da Embratel, temos a herança portuguesa colonial ressaltada. Quem detém o capital, mais uma vez, é o português e não a moça negra, que nem telefone próprio possui. Ela já não é mais escrava, mas também não é patroa.

Não é somente pelo modo de se vestir e agir que podemos constatar a ideologia operando em favor da maioria. A fala também revela o tipo de relação estabelecida entre os personagens. São os personagens negros que perguntam. E quem tem a resposta? Os brancos (o casal ou o português). Não tem sido assim há séculos? Os brancos costumam ter as respostas; são eles que têm mais acesso às escolas e universidades; são eles que decidem e mandam. Ao que tudo indica, às minorias resta fazer, obedecer, e quando muito perguntar.

As minorias podiam ser excluídas das propagandas se não fosse o fato de que o objetivo delas é absorver uma fatia potencial de mercado, enfim, potencializar lucros. Tanto a propaganda Blue Steel quanto da Embratel aproveitam o uso de personagens negros para estimular a venda. Uma pesquisa relatada por Sodré (1999) revelou que cerca de $71 \%$ de entrevistados afirmavam a disposição de adquirir determinados produtos toda vez que a sua propaganda incluía um negro. Falando eticamente, incluir negros em propagandas seria um aspecto positivo; no entanto, veicular imagens reforçando aspectos discriminatórios é contribuir para o crescimento do abismo das desigualdades sociais.

O pior de tudo é que ambas as propagandas reforçam o problema já salientado por Sodré (1999) - da autodiscriminação por parte das minorias, devido à internalização de imagens negativas sobre si mesmas, pois se trata de processos inconscientes de autodesvalorização. Se as imagens veiculadas das minorias são discriminatórias, como têm sido na maioria das vezes, como poderão as minorias valorizar a si mesmas, a gostarem de ser negras, mulheres, judias ou índias? Ou como poderão mudar do caráter anômico para nômico? As alternativas são escassas, já que a mídia continua apontando como solução que as minorias 
Psicologia \& Sociedade; 14 (2): 74-94; jul./dez.2002

desfavorecidas economicamente peçam favores (o telefone do Seu Joaquim) ou consumam bens que custem quase a metade de um salário mínimo (o jeans).

Nesse emaranhado dos níveis: real, representacional e ideológico, as relações de dominação vão sendo criadas e reforçadas. As propagandas em questão podem ser, então, mais uma das formas simbólicas que estão a serviço do poder.

\section{ALGUMAS CONSIDERAÇÕES PARA FUTURAS REFLEXÕES}

Como vimos, as propagandas Blue Steel e Embratel 21 pretendem suscitar o desejo em um grupo de pessoas que geralmente sofrem discriminações na sociedade e que, na maioria das vezes, não consegue ter acesso aos mesmos capitais que a maioria costuma ter: boas escolas, roupas da moda e de griffe, telefone próprio, empregos com salário e status. Talvez comprando aquele jeans, ou fazendo um 21, aquela minoria consiga ser ou parecer com a maioria, ou pelo menos não ser tão excluída.

Identificar áreas problemáticas na comunicação de massa pode não nos ajudar a evitar que os mesmos problemas se repitam, porém salientar e até aprender que minorias têm suas próprias características e que ser diferente não é algo ruim, negativo. Pode nos auxiliar a sermos mais sensíveis às problemáticas que as minorias enfrentam. Conscientizar-se dos estereótipos e preconcepções sociais que perpassam as propagandas é vital para que as culturas sobrevivam. Nesse sentido, a psicologia social pode trazer ricas contribuições aos estudos críticos sobre meios de comunicação de massa.

Como lembra Mulvaney (1994), a tendência a valorizar a cultura do outro como inferior a nossa é, talvez, a maior barreira a ser evitada. O desafio para melhorar a comunicação (intercultural) é através da consciência e respeito a outras culturas, ao invés de avaliá-las. Acima de tudo, a comunicação exige responsabilidade moral (e ética, acrescentamos).

Na propaganda Blue Steel, vimos que ao se mostrar membros de um grupo minoritário como possíveis "assaltantes", desprovidos de saber, como "inúteis" ou desempregados, reforça-se as discriminações sociais já vivenciadas pelos grupos minoritários. A propaganda perpetua uma imagem negativa dos grupos minoritários, estabelecendo e reforçando o medo da maioria frente à minoria. Essa é uma tentativa de transformar os "desviantes". É tentar fazer com que eles adotem os pontos de vista da maioria. Isto é: fazer com que eles se conformem às normas da maioria. 
Roso, A.; Strey, M.N.; Guareschi, P.; e Bueno, S.M.N.

"Cultura e ideologia: a mídia revelando estereótipos raciais de gênero"

O desviante passa a ser mostrado como aquele que tem desejo de ser como a maioria. Ele já não resiste mais às pressões do grupo; e desta forma, não permanecerá independente. A influência social não somente pode servir ao controle social e ajudar que cada um se adapte a uma realidade social determinada, mas contribui para a mudança social. Não, contudo, uma mudança social positiva, no sentido cultural, onde as minorias podem preservar sua cultura, seu modo de expressão através da vestimenta e modo de ser, mas uma tentativa de mudar o diferente, para que o diferente se torne a massa, transforme-se em maioria.

Esquecemos constantemente que os grupos minoritários têm suas próprias características culturais (modo de vestir, de andar, etc.) que os definem como um grupo distinto e é nessa distinção que reside seu aspecto específico, sua identidade característica. A propaganda Blue Steel parece querer "desminorizar" essas pessoas, ou seja, transformar suas características em características da maioria: vestir-se igual a eles, ser igual a eles, ter os mesmos desejos, comprar nas mesmas lojas.

Em um mundo onde a globalização tem sido cada vez mais imposta às pessoas - seja através de propagandas ou de qualquer outro meio precisamos parar, pensar e refletir se o que realmente queremos é uma população de andróides, ou se queremos que as culturas (e sub-culturas) sobrevivam. A tentativa de padronizar vestimentas, tecnologias, modo de viver, de pensar e agir não é somente discriminação ou exclusão; é reforçar uma moral estética e esquecer da ética na produção de formas simbólicas. O intuito é obter grandes vendas e lucro, assassinando culturas, massificando, cada vez mais, as pessoas.

Acreditamos que também é papel dos(as) psicólogos(as) sociais e de profissionais das ciências sociais olhar com olhos críticos e questionar as formas simbólicas para que seus conteúdos não sejam massificadores e reforçadores de relações de dominação de gênero, raça, classe ou qualquer outro tipo de dominação que possa ser veiculado e reificado através dos meios de comunicação de massa. Sem olhos críticos podemos pisar em falso e seremos engolidos/as pelo próprio sistema. Faz-se urgente parar de pensar exclusivamente de maneira capitalista e avançar no pensamento ético-crítico. 
Psicologia \& Sociedade; 14 (2): 74-94; jul./dez.2002

\section{REFERÊNCIAS BIBLIOGRÁFICAS}

. BARTHES, R. Mitologias (8ed.). Rio de Janeiro: Bertrand, 1989.

. BERGER, A. Media Analysis techniques. (The Sage Commtext Series; v.10). Newbury Park, CA: Sage, 1991.

. BERSTEIN, B. A estruturação do discurso pedagógico. Classe, códigos e controles. Petrópolis: Vozes, 1996.

. DOMS, M. ,\& MOSCOVICI, S. Innovación e influencia de las minorias. In S. Moscovici. Psicología social I (2 ${ }^{\text {nd }}$ reimpresión, pp. 71--116). Barcelona: Paidós, 1991.

. FISKER J. Television culture. London-New York: Routledge, 1990.

. HALL, S. The spectable of the 'other'. In S. Hall (Ed.). Representation. Culture representations and signifying practices (pp.223-290). London: Sage-The Open University, 1997.

. HECK, M. C. The ideological dimension of media messages. In S. Hall, D. Hobson, A. Lowe, \& P. Willis (eds.). Culture, media, language (pp. 122-127). London: Routledge, 1996.

. JOHNSON, S. Anti-Bias Talk Noticed In Civil-Union Debate. New York Times, Nov. 13, A14, 2000.

. Journal of Psychosocial Nursing \& Mental Health Services Tattoos and piercing off psychopathology clues, v.36 (12), p. 9, Dec. 1998.

. LEVINE, J. M., \& PAVELCHAK, M. A. Conformidad y obediencia. In S. MOSCOVICI. Psicología Social (v.1, pp.41-70). Paidós: Barcelona, 1991.

. Modern Healthcare HIV tattoo is no reason to fire an employee - EEOC; Vol. (40), p.4,Oct 4, 1993.

. MORELLO, C. Mormons back California measure that would ban gay marriages. USA Today, Out. 4, 04A, 1999.

. MOSCOVICI S. Psicología social I ( $2^{\text {nd }}$ reimpresión). Barcelona: Paidós, 1991.

. - Social representations. Explorations in social psychology. Cambridge: Polity Press, 2000. 
Roso, A.; Strey, M.N.; Guareschi, P.; e Bueno, S.M.N.

"Cultura e ideologia: a mídia revelando estereótipos raciais de gênero"

. MULVANEY, B. Gender Differences in Communication: An Intercultural Experience. Florida: Florida Atlantic University - Department of Communication, 1994.

. SODRÉ, M. Claros e escuros. Identidade, povo e mídia no Brasil. Petrópolis: Vozes, 1999.

. The Weekly Standard. Tatoo discrimination?, Jan 28, v.7 (19), p.3, 2002.

. THOMPSON, J. B. Ideologia e cultura moderna: Teoria social crítica na era dos meios de comunicação de massa. Rio de janeiro: Vozes, 1995.

. - A mídia e a modernidade. Uma teoria social da mídia. Petrópolis: Vozes, 1998.

\section{ANEXO}

\section{Blue Steel}

Inicia com um casal de homem e mulher, caminhando pela calçada de um bairro aparentemente novaiorquino. $O$ tom musical aumenta, ficando cada vez mais tenso, quando eles avistam um grupo de quatro jovens, perto de uma escada. $O$ casal se dá as mãos. O grupo de rapazes se movimenta, um deles dá um salto para o cordão da calçada, para dar passagem ao casal. Os outros caminham em direção ao casal e circundam-no. Um dos rapazes pergunta ao rapaz acompanhado da moça: "Where did you get those jeans, man?". Na tela, há a tradução: Ei, onde você comprou esse jeans? Aparece, no pé da tela, o slogan da marca do jeans (Blue Steel). Na mesma cena, entra o slogan da loja (Renner) onde o jeans está sendo vendido.

\section{Embratel 21}

Inicia com uma mulher anunciando o novo serviço da Embratel: "A partir de julho, o Brasil inteiro vai ficar ligado no 21 ”. Na cena seguinte, outra mulher entra em um armazém e diz para o dono do estabelecimento: "Oi! Seu Joaquim. Posso fazer um 21 para Salvador". Ele responde: "Oh, cachopa. É claro!". Quando a moça vai para o telefone, fica de costas para seu Joaquim e ele faz o sinal da cruz, dizendo: "Oh! minha Santa Clara!”. Entra em cena sua esposa, que esta atrás do balcão, e pergunta: "O que é isso Joaquim?!". Ele responde: "E só o 21 que ela vai fazer lá pra terra dela. Está com saudade!". A esposa diz: 
$\overline{\overline{ }}$ Psicologia \& Sociedade; 14 (2): 74-94; jul./dez.2002

"Saudade! Venha fazer outro 21". O foco está na esposa, que segura um rolo de massa na mão esquerda. A câmera volta a focar na moça, que se despede: "Tchau seu Joaquim, muito obrigado". Seu Joaquim diz: "Apareça!". A esposa retruca: "Tu vai voltar para Portugal e depois não adianta fazer 21 ...". No final, volta a protagonista dizendo: "A partir de julho, faz um 21", e aparece, no pé da tela, o slogan da marca da Embratel 21.

\section{NOTAS}

${ }^{1}$ Não devemos confundir o termo inocentemente com passivamente. Thompson (1998) enfatiza que "a recepção deveria ser vista como uma atividade (... ). Mesmo que os indivíduos tenham pequeno ou quase nenhum controle sobre os conteúdos das matérias simbólicas que lhes são oferecidas, eles os podem usar, trabalhar, reelaborar de maneiras totalmente alheias às intenções ou aos objetivos dos produtores"(p.42).

${ }^{2}$ Pan é a abreviatura da panorâmica; down significa 'para baixo'. Então, pan down significa o movimento da câmera, que está parada na horizontal, em sentido vertical, ou seja, em direção ao solo.

${ }^{3}$ Uma das autoras desse artigo estava morando em Nova Iorque quando a catástrofe do World Trade Center, em 11 de setembro de 2002, ocorreu. Após o atentado terrorista, o status de Nova Iorque como centro turístico e empresarial, no mundo todo, sofreu abalo, revelando a fragilidade da nação e rompendo com a imagem de inatingibilidade americana (nos sentidos econômico, social e bélico). Entretanto, na visão de muitos nova-iorquinos, o status da cidade foi revigorado através do nacionalismo e o sabor de mistura étnica e racial tornou-se mais evidente, uma mistura preenchida, ao mesmo tempo, por elementos de coesão e sectarismo.

${ }^{4}$ Não devemos confundir o termo inocentemente com passivamente. Thompson (1998) enfatiza que "a recepção deveria ser vista como uma atividade (... ). Mesmo que os indivíduos tenham pequeno ou quase nenhum controle sobre os conteúdos das matérias simbólicas que lhes são oferecidas, eles os podem usar, trabalhar, reelaborar de maneiras totalmente alheias às intenções ou aos objetivos dos produtores"(p.42). 
Roso, A.; Strey, M.N.; Guareschi, P.; e Bueno, S.M.N.

"Cultura e ideologia: a mídia revelando estereótipos raciais de gênero"

Adriane Roso é Psicóloga social aluna do Programa de PósGraduação em Psicologia da Pontifícia Universidade Católica do Rio

Grande do Sul. O endereço eletrônico da autora é roso@fulbrightmail.org ou adrianeroso@yahoo.com

Marlene Strey é Professora do Programa de Pós-Graduação em Psicologia da Pontifícia Universidade Católica do Rio Grande do Sul.

O endereço eletrônico da autora é streymn@pucrs.br.

Pedrinho Guareschi é Professor do Programa de Pós-Graduação em Psicologia da Pontifícia Universidade Católica do Rio Grande do Sul.

O endereço eletrônico da autor é guareschi@pucrs.br

Sandra Bueno é Socióloga; Secretaria da Saúde do Estado do

Rio Grande do Sul.

Adriana Roso, Marlene Neves Strey, Pedrinho Guareschi e Sandra M. Nora

Bueno

Cultura e ideologia: a mídia revelando estereótipos raciais de gênero.

Recebido: $15 / 8 / 2002$

$1^{\text {a }}$ revisão: $25 / 10 / 2002$

Aceite final: 17/12/2002 